\title{
Electron transfer processes of coadsorbed Anthracene and N,N-Dimethylaniline on titania-silica
}

\author{
Anna Eremenko, ${ }^{1, \dagger}$ Natalie Smirnova, ${ }^{1}$ Oksana Yakimenko, ${ }^{1}$ \\ Galina Starukh, ${ }^{1}$ David R. Worrall, ${ }^{2}$ and Siân L. Williams ${ }^{2}$ \\ ${ }^{1}$ Institute of Surface Chemistry of National Ukrainian Academy of Sciences, 03164 Kiev, Ukraine \\ ${ }^{2}$ Department of Chemistry, Loughborough University, Loughborough, Leicestershire LE11 3TU, UK
}

\begin{abstract}
The effect of titania-silica binaries on the processes of PET and the decay kinetics of the Anthracene (An) fluorescence and An radical cation in presence of the co-adsorbed electron donor N,Ndimethylaniline (DMA) has been studied. The fluorescence of excited An adsorbed on pure silica is quenched by the addition of DMA, while co-adsorption of DMA on Ti/Si binaries resulted in increase of fluorescence intensity of adsorbed An. We suggest that competitive adsorption between DMA and An results in DMA occupying more active "titania" sites causing the shift of An molecules to weaker adsorption sites located on the silica support. An and DMA molecules being adsorbed simultaneously on the surface, effectively produce reduced titanium ions due to an electron transfer process. These data appear to lend weight to the suggestion of a pre-exciplex An-DMA state on the surface and effective PET from the excited molecular pair to the acceptor sites on the surface. These sites may be titania aggregates, or titania ions when there is a low content of $\mathrm{Ti}$ in the binaries.
\end{abstract}

\section{INTRODUCTION}

Interfacial photoinduced electron transfer (PET) reactions on the surface of disperse solids are governing stages in processes involving the storage of light energy and separation of charges [1, 2]. Such reactions are of great theoretical and practical interest as, for instance, the adsorption of molecular dyes to the surface of wide band gap semiconductors can result in the sensitisation of the semiconductor to visible light $[3,4]$. Photoinduced charge transfer and charge separation in heterogeneous media can be enhanced by the process of adsorption and incorporation of guest molecules. PET reactions between adsorbed anthracene (An) and pyrene (Py) with N,N-dimethylaniline (DMA) in porous silica gel have been examined by fluorescence quenching $[5,6]$ and by transient absorption techniques [7-10]. The quenching on silica surfaces is found to be diffusion controlled and gives rise to exciplex formation on silica surfaces with the diffusion constant $\mathrm{D}=1.04 \times 10^{-7} \mathrm{~cm}^{2} / \mathrm{s}$ at room temperature [8]. This was attributed to DMA movement on the silica surface, since pyrene is virtually immobilized on this time scale [8]. Fluorescence quenching was measured at different sample temperatures. The diffusion motion of reactants was confirmed by a strong temperature effect on the quenching kinetics: i.e. cooling shuts down the reaction [8], and heating to $60-80{ }^{\circ} \mathrm{C}$ speeds up the reaction [8], as well as by means of the photobleaching of pyrene in presence of $\mathrm{N}, \mathrm{N}$-dimethylaniline on the silica surface [8].

Such a Langmuir-Hinshelwood type of surface reaction is described quantitatively using a two dimensional

†E-mail: annerem@mail.kar.net kinetics model. Surface diffusion of DMA is found to be thermally activated and related to the hydrogen bonding interaction between DMA and surface hydroxyl groups. Properties of exciplex emission such as the position of the maximum and the quantum yield have been used to characterise the surface environment. Deactivation of the exciplex on silica surfaces via charge recombination is understood in terms of photo assisted electron transfer theory. The low yield of ionic products from dissociation of the contact ion pairs of the exciplex ${ }^{1}\left(\mathrm{Py}_{-} \mathrm{DMA}^{+}\right) *$ was attributed to the lack of solvation and the low mobility of ionic species on the surface.

The production of the An radical cation on the silica surface has been shown to be via a multiphoton process both by a laser dose study and by millisecond flash lamp experiments [7-10]. Addition of the electron donor DMA greatly accelerates the rate of An radical cation decay via an electron transfer mechanism. Inspection of the emission spectra of An in the presence of the electron donor triphenylamine (TPA) adsorbed on silica gel showed the formation both of An excimer and (An-TPA)* exciplex which has been formed due to adsorption of TPA and An in close proximity on the silica surface [10].

Recently we have studied the photophysics of anthracene adsorbed on photocatalytic silica-titania (Ti/Si) mixed oxide systems prepared by two different methods: a sol-gel synthesis and an impregnation route [11]. The observed photophysics depend upon the method of synthesis, with the sol-gel prepared samples resulting in enhanced An radical cation formation via static excited singlet state quenching. Fluorescence quenching of the excited anthracene occurs on both 
Ti/Si surfaces and clearly shows a dependence on titania content. Similar fluorescence behaviour of adsorbed Pyrenemethanol on titania-silica binaries has been observed [12].

A sol-gel route is often used for the preparation of ultrasmall isolated semiconductor particles (SP) in various heterogeneous environments as reactive heterogeneous media [13-15]. Two types of titania species are possibly present in sol-gel prepared binary oxides: segregated microdomains and isolated species [15, 16]. Mixed silica-titania compositions represent a novel class of photocatalysts and supports [1720]. The enhanced photocatalytic activity of silicasupported semiconductors is attributed by Kisch and co-authors to an electronic semiconductor-support interaction (SEMSI) mediated through surface $\mathrm{Si}-\mathrm{O}-$ semiconductor bonds, which alters the bandgap energy and flatband potential [21].

The main goal of this work is to study the effect of titania-silica binaries on the processes of PET and the decay kinetics of the An fluorescence and An radical cation in presence of the co-adsorbed electron donor $\mathrm{N}, \mathrm{N}$-dimethylaniline DMA.

\section{MATERIALS AND METHODS}

Titania-silica compositions ( $\mathrm{Ti} / \mathrm{Si}$ ) with 1,5 and $8 \mathrm{wt} \%$ of $\mathrm{TiO}_{2}$ were prepared via a sol-gel route by dropwise addition of titanium tetraisopropoxide (TPOT) to the stable colloidal silica Ludox (Aldrich Chemical Company) in the presence of aqueous $\mathrm{HCl}$; after $4 \mathrm{hrs}$ of mixing, these solutions were rotary evaporated at $60{ }^{\circ} \mathrm{C}$, and then dried consecutively at 100,300 and $500^{\circ} \mathrm{C}$. Pure silica was prepared from Ludox by this method for comparison. Specific surface areas were measured using low-temperature desorption of Ar and were determined as $135 \mathrm{~m}^{2} / \mathrm{g}$.

Anthracene and N,N-dimethylaniline were adsorbed on the solid surfaces of dried silica and $\mathrm{Ti} / \mathrm{Si}$ samples from cyclohexane solutions. After equilibration for $4 \mathrm{hrs}$, the solvent was removed under vacuum and the samples dried to $1 \times 10^{-3}$ mbar. Samples were then sealed within quartz cuvettes under vacuum. Loadings of Anthracene of $3.5 \times 10^{-6} \mathrm{~mol} / \mathrm{g}$, and DMA $4 \times$ $10^{-6} \mathrm{~mol} / \mathrm{g}$, on the support surface were used throughout.

The nanosecond diffuse reflectance laser flash photolysis apparatus has been described previously in detail elsewhere [20]. Excitation of the samples was with the third harmonic $(355 \mathrm{~nm}, 20 \mathrm{~mJ} /$ pulse) of a Continuum Surelite I Nd:YAG laser. The pulse energy was attenuated by interposing microscope slides between laser and sample. Diffusely reflected analysing light from a $275 \mathrm{~W}$ xenon arc lamp (Oriel) was collected and focused onto the slit of an f/3.4 grating monochromator (Applied Photophysics) and detected with a side-on photomultiplier tube (Hamamatsu R928).
Signal capture was by a TDS420D (Tektronix) or an LT364 (LeCroy) digital oscilloscope interfaced via GPIB to an IBM-compatible PC.

Ground state diffuse reflectance spectra were recorded using a Perkin-Elmer Lambda Bio 40 spectrophotometer equipped with a Spectralon integrating sphere.

Fluorescence spectra were recorded using a Spex FluoroMAX spectrofluorimeter using front surface geometry.

Time correlated single photon counting measurements were performed using a Model 199 fluorescence lifetime spectrometer (Edinburgh Instruments) with a nitrogen lamp fill and an excitation wavelength of $337 \mathrm{~nm}$. Lamp reference spectra were recorded by scattering from the respective sample.

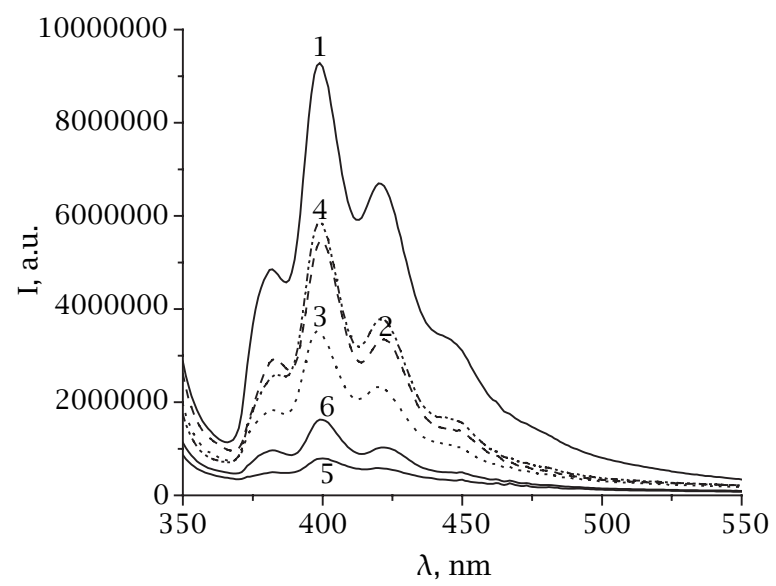

Figure 1. Fluorescence spectra of Anthracene $(1,3,5)$ and Anthracene with coadsorbed N, N-Dimethylaniline $(2,4,6)$ on silica $(1,2), 1$ wt.\% $\mathrm{TiO}_{2} / \mathrm{SiO}_{2}(3,4), 5 w t . \% \mathrm{TiO}_{2} / \mathrm{SiO}_{2}$ $(5,6)$.

\section{RESULTS AND DISCUSSION}

3.1. Fluorescence quenching. The fluorescence of excited An adsorbed on pure silica is quenched by the addition of DMA (Figure 1, sp. 2) while co-adsorption of DMA on Ti/Si binaries resulted in an unexpected increase in the fluorescence intensity of the adsorbed An in proportion with the amount of added amine (Figure 1, sp. 4,6).

The fluorescence decay profiles of adsorbed An are not greatly affected by titania content (Figure 2), although the fluorescence intensity of adsorbed An decreases significantly with increasing Ti concentration (Figure 1, spp. 1,3,5) demonstrating that the fluorescence quenching mechanism is predominantly static in nature.

On the basis of the average ratio of adsorbed anthracene to titania ions ( $1: 2000$ for $1 \%$, and $1: 10000$ for $5 \%$ calculated per gram of mixed composition), it is expected on purely statistical grounds that there are 


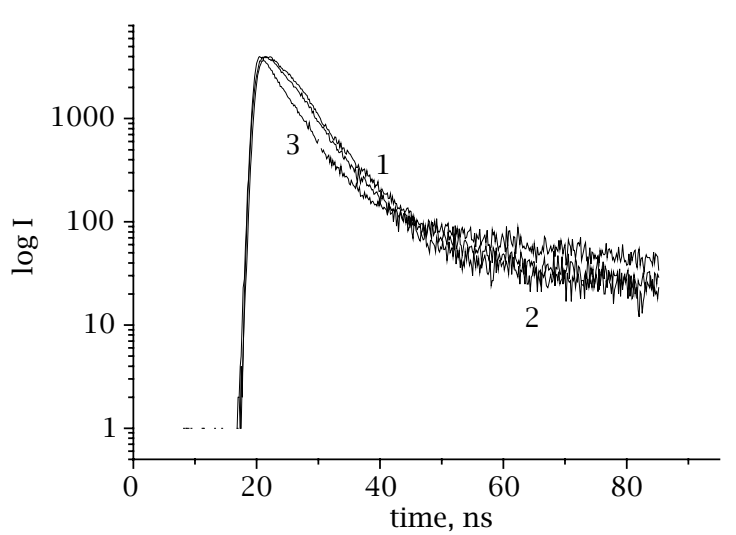

Figure 2. Fluorescence decay profiles of adsorbed Anthracene depend on $\mathrm{TiO}_{2}$ wt.\% in $\mathrm{TiO}_{2} / \mathrm{SiO}_{2}: 0-1 ; 1-2 ; 5-3$.

a significant proportion of anthracene molecules adsorbed at titania sites, where electron transfer quenching of the fluorescence occurs.

In contrast to the case of An fluorescence decay on $\mathrm{Ti} / \mathrm{Si}$ surfaces (Figure 2), in the case of An-DMA/SiO ${ }_{2}$ the fluorescence decay rate is increased relative to that of An adsorbed alone on $\mathrm{SiO}_{2}$, demonstrating a dynamic quenching in this system. In the case of the Ti/Si binaries, the decay rate is essentially independent of both Ti and DMA (Figure 3). We suggest that the increase in fluorescence intensity observed on addition of DMA to the An/Ti/Si system arises from the fact that the DMA competes efficiently with An molecules for adsorption to the Ti/Si surface, occupying the more active "titania" sites causing the relocation of An molecules to weaker adsorption sites located on the silica support where their fluorescence is not quenched by electron transfer. This demonstrates the important role of the adsorption process of the contaminant organic molecules in the processes of photocatalysis on the semiconductor composites.

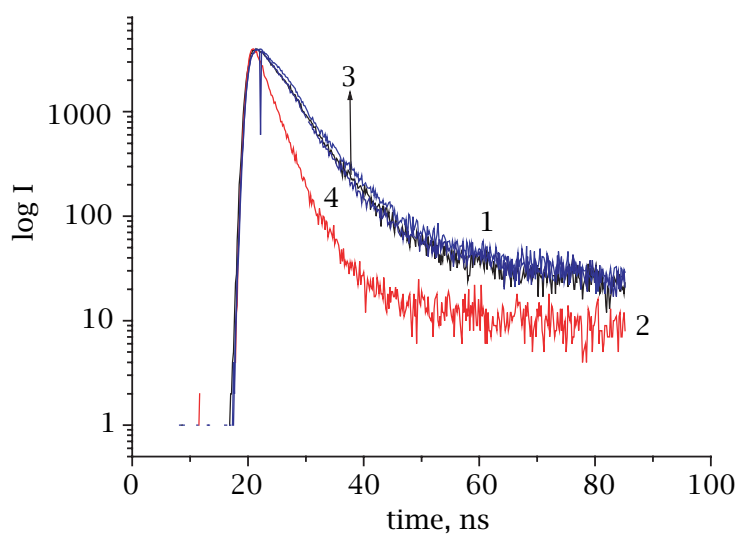

Figure 3. Fluorescence decay profiles of adsorbed Anthracene $(1,3)$ and Anthracene with coadsorbed N, NDimethylaniline $(2,4)$ depend on $\mathrm{TiO}_{2}$ wt.\% in $\mathrm{TiO}_{2} / \mathrm{SiO}_{2}$ : $0-1,2 ; 1-3,4$.
Thus, the observed quenching effect of the "titania" sites on the fluorescence of An in the presence of coadsorbed DMA decreases with increasing DMA loading. The dynamics of this competitive adsorption are the subject of further study.

As we can see in Figure 1, the intensity of An fluorescence increases with increasing DMA content on $\mathrm{Ti} / \mathrm{Si}$ surfaces but does not increase so far as to the initial intensity seen on pure silica. The intensity of monomer fluorescence on the Ti/Si surface increases successively with increasing DMA concentration from $4 \times 10^{-6}$ to $4 \times 10^{-4} \mathrm{~mol} / \mathrm{g}$. When the concentration of DMA is greater than $4 \times 10^{-3} \mathrm{~mol} / \mathrm{g}$, the intensity of the An fluorescence sharply decreases. In this case, dynamic bimolecular quenching of the An fluorescence by DMA is assigned as the dominant mechanism. We suggest that in this case the bimolecular reaction between An and DMA occurs in the 3D liquid region when a monolayer of DMA completely covers the surface. It is interesting to stress that An/DMA exciplex emission has not been detected on the $\mathrm{Ti} / \mathrm{Si}$ surface, in contrast to the case on the pure silica surface. Recently the existence of adsorbed An and N,N-diethylaniline (DEA) disposed close to one another and their mutual electronic influence at the energy of binding with pure silica aerosil surface have been demonstrated [22].

Titanium ions affect the nature of surface active centers and define the mechanism of adsorption as a primary step of photocatalysis. Centers of strong adsorption for organic molecules are formed on the $\mathrm{Ti} / \mathrm{Si}$ surface. The An and DMA molecules are adsorbed as single complexes with titanium ions, aggregates or weak Van der Waals intermolecular complexes. We can suggest the existence of closely spaced An-DMA molecules near titania active centers. The affinity of DMA to the surface $\mathrm{OH}$ group is high resulting in the suppression of the diffusion of DMA at least to the point of the formation of a monolayer of adsorbed molecules. This is an important conclusion for the understanding of the role of absorption of real contaminants from the environment on the surface of the photocatalyst, and their mutual distribution and mobility.

3.2. Diffuse reflectance spectra. The visible region of the ground state diffuse reflectance spectra of adsorbed species demonstrates the signals of An radical-cation ( $425 \mathrm{~nm}$ and $715 \mathrm{~nm}$, Figure 4, sp. 4) after laser pulse action, and of the injected electron (resulting in the formation of $\mathrm{Ti}^{3+}$ ) in the presence of DMA $(610 \mathrm{~nm}, \mathrm{sp} .3)$. A low intensity signal assigned to $\mathrm{Ti}^{3+}$ is also observed in the ground state (sp. 2). The elementary reactions can be written as

$\mathrm{An}_{\mathrm{ads}}+\mathrm{h} v \longrightarrow \mathrm{An}^{*}+\mathrm{h} v \longrightarrow \mathrm{An}^{+} \cdot$ Formation of radical cation of An

$\mathrm{DMA}+\mathrm{TiO}_{2} \longrightarrow$ DMA--- $\mathrm{TiO}_{2} \longrightarrow \mathrm{Ti}^{3+}$ Charge transfer from amine to titania within adsorption complex 


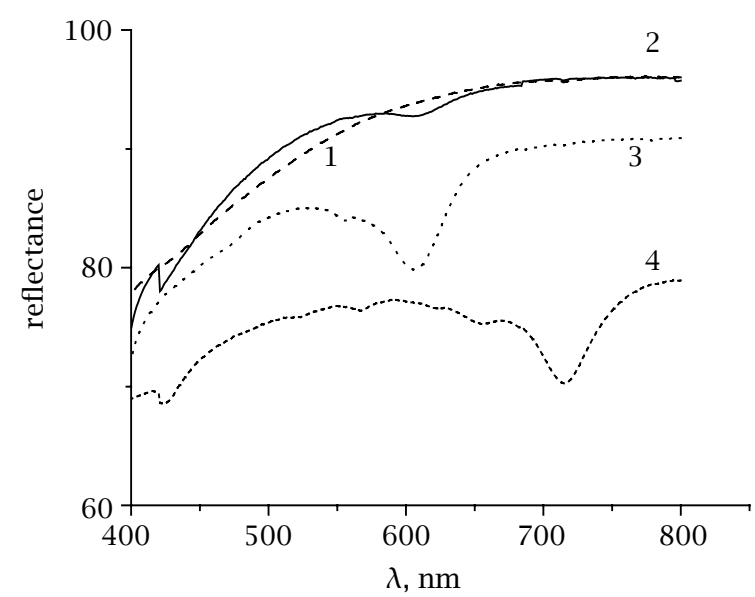

Figure 4. Diffusion-reflectance spectra of Anthracene $(1,4)$ and Anthracene with coadsorbed N, N-Dimethylaniline $(2,3)$ on the surface of $1 \% \mathrm{TiO}_{2} / \mathrm{SiO}_{2}$ before $(1,2)$ and after $(3,4)$ laser pulse action.

$\mathrm{An}_{\mathrm{ads}}+\mathrm{DMA}_{\mathrm{ads}}+\mathrm{h} v \longrightarrow(\mathrm{An} \cdots \mathrm{DMA})_{\mathrm{ads}}^{*} / \mathrm{TiO}_{2} \longrightarrow$ $\mathrm{An}+\mathrm{DMA}^{+} \cdot-\mathrm{Ti}^{3+}$ Formation of "pre-exciplex" and charge injection to titania

In the proposed scheme, DMA molecules interact with Ti-centres with charge transfer to titania. The excited molecular pair (An-DMA)* is a more effective electron donor than separate An and DMA adsorbed on the surface.

Thus, An and DMA molecules being adsorbed simultaneously on the surface, effectively produce reduced titanium ions due to an electron transfer process. These data appear to lend weight to the suggestion of a pre-exciplex An-DMA state on the surface and effective PET from the excited molecular pair to the acceptor sites on the surface. - These sites may be titania aggregates, or titania ions when there is a low content of $\mathrm{Ti}$ in the binaries.

3.3. Transient absorption. As discussed in detail in previous publications [7, 9, 10], upon excitation at $355 \mathrm{~nm}$ of anthracene adsorbed on silica gel the transient difference spectrum shows the presence of two distinct spectral features: triplet-triplet absorption peaking at $420 \mathrm{~nm}$ and radical cation absorption with the main peak located at $715 \mathrm{~nm}$. Excitation of anthracene on titania-silica surfaces also results in the production of both triplet-triplet $(420 \mathrm{~nm})$ and radical cation $(715 \mathrm{~nm})$ absorption (Figure 5) [11].

Coadsorption of DMA produces a significant change in the observed transient absorption spectra. The An radical cation absorption band disappears and a new band attributable to the radical cation of DMA is observed at $460 \mathrm{~nm}$ on both silica and titania-silica surfaces (Figure 6).

It is important to note that flash photolysis of DMA adsorbed alone on silica and on the Ti/Si surface does

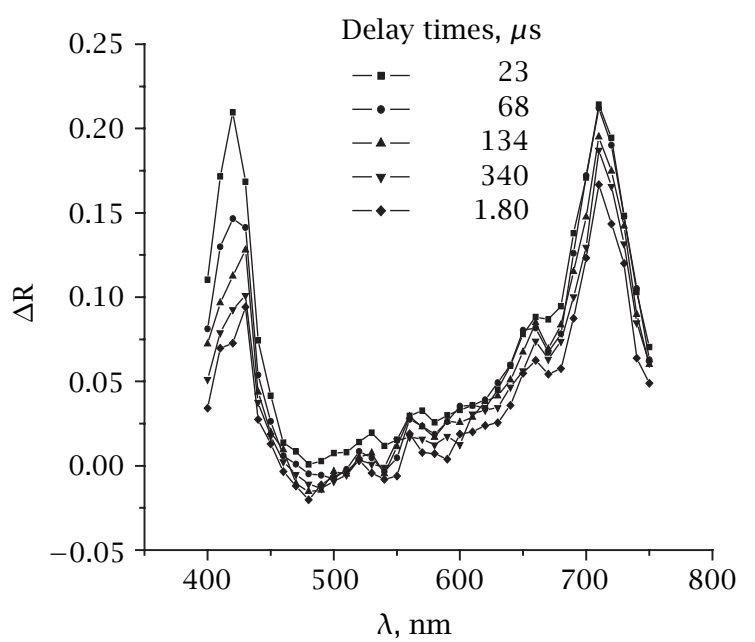

Figure 5. Time-resolved transient difference spectra showing reflectance change following laser excitation at $355 \mathrm{~nm}$ of Anthracene adsorbed on the surface of 1 wt.\% $\mathrm{TiO}_{2} / \mathrm{SiO}_{2}$.

not result in DMA radical cation formation radiation due to the lack of one-photon absorption of $355 \mathrm{~nm}$. When An and DMA are adsorbed, the affinity of DMA to the excited $\mathrm{An}^{*}$ molecule is higher than that to the surface $\mathrm{OH}$ center on which DMA has been located. We suggest that $\mathrm{DMA}^{+}$- is formed from the "pre-exciplex" $(\mathrm{An} \bullet \mathrm{DMA})^{*}$ state on the $\mathrm{Ti} / \mathrm{Si}$ surface. In a previous publication [24] we demonstrated DMA radical cation formation from excitation of such species. After the laser pulse, electron transfer occurs from DMA to excited $\mathrm{An}^{*}$. It is reasonable to expect the free radical ions from the ionic dissociation, i.e. $\mathrm{An}^{-*}$ and $\mathrm{DMA}^{+*}$ are produced in this pair. However the An anion radical is not observed in the transient absorption spectrum because of the higher electron affinity of silica and still further of the Ti/Si surface compared to that of An [23].

The formation of DMA radical cation following the absorption of $355 \mathrm{~nm}$ radiation is not dependent in a simple sense upon the presence of titania (Figure 6). Lifetimes of the DMA radical cation calculated using a monoexponential approximation to the decay curves decrease in presence of titania.

\section{CONCLUSION}

The fluorescence of excited An adsorbed on pure silica is quenched by the addition of DMA, while co-adsorption of DMA on $\mathrm{Ti} / \mathrm{Si}$ binaries resulted in increase of fluorescence intensity of adsorbed An. Decay curves of An fluorescence on $\mathrm{Ti} / \mathrm{Si}$ surfaces did not change in the presence of DMA, in contrast to the case in $\mathrm{An}-\mathrm{DMA} / \mathrm{SiO}_{2}$ compositions, where quenching is dynamic. We suggest that competitive adsorption between DMA and An results in DMA occupying more active "titania" sites causing the shift of An molecules to weaker adsorption sites located on the silica support. The An 

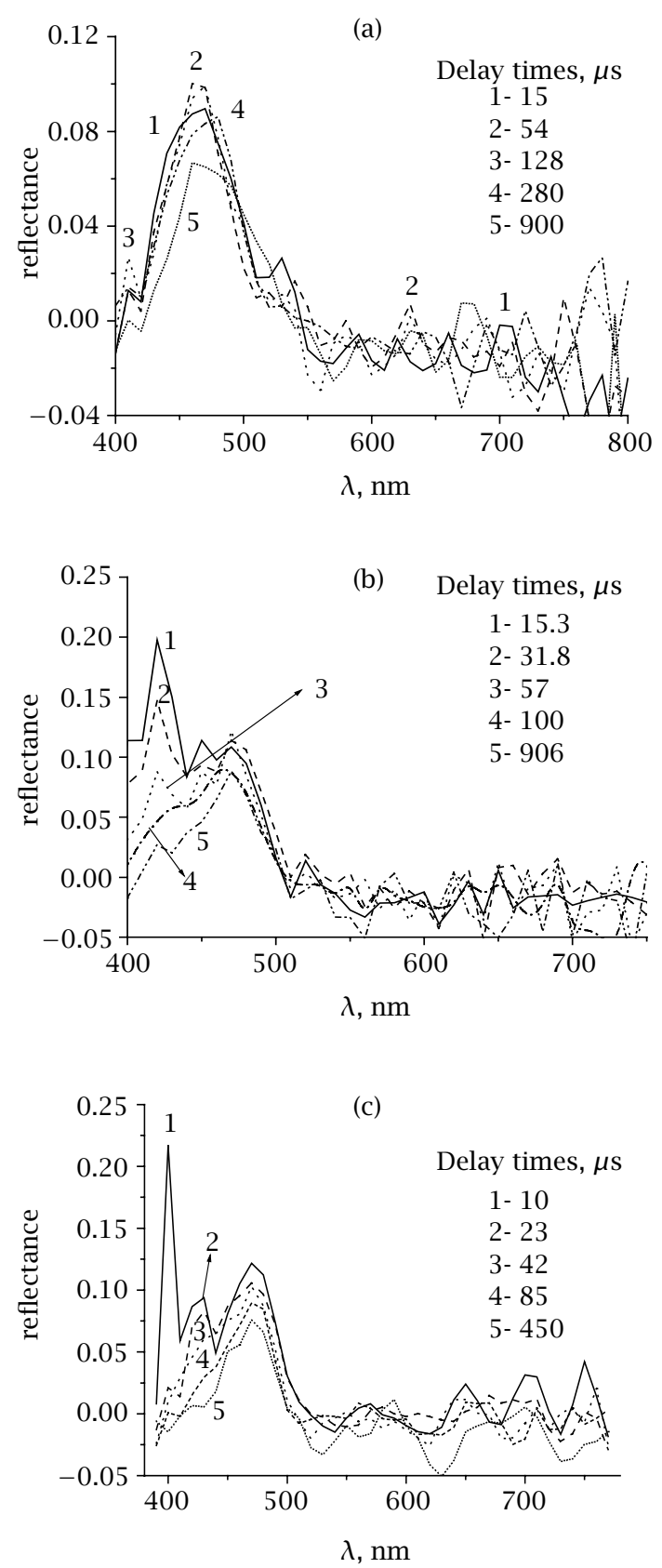

Figure 6. Time-resolved transient difference spectra showing reflectance change following laser excitation at $355 \mathrm{~nm}$ of Anthracene with coadsorbed N, N-Dimethylaniline on silica-(a); $\mathrm{TiO}_{2} / \mathrm{SiO}_{2}$ with 1 wt.\% of $\mathrm{TiO}_{2}-(b) ; \mathrm{TiO}_{2} / \mathrm{SiO}_{2}$ with 5 wt.\% of $\mathrm{TiO}_{2}-(c)$.

radical cation is not observed in the presence of coadsorbed electron donor DMA on the Ti/Si binaries surface, at least when An : DMA ratio was $1: 1$, due to formation of closely-spaced "pre-exciplex" molecular pairs. Direct evidence of electron injection from adsorbed An-DMA pair to titania particles has been obtained in the diffuse reflectance spectra on the surface of $\mathrm{Ti} / \mathrm{Si}$ samples. When An is adsorbed alone, the $\mathrm{Ti}^{3+}$ signal did not appear probably because of effective back ET from titania to the radical cation of An. This study demonstrates the important role of adsorption equilibrium of contaminant organic molecules in photocatalytic processes involving semiconductor composites.

\section{REFERENCES}

[1] M. Anpo and T. Matsuura (eds.), Photochemistry on Solid Surfaces, Elsevier, Amsterdam, 1989.

[2] V. Ramamurthy (ed.), Photochemistry in Organized and restricted Media, VHCH, NY, 1991, p. 535.

[3] A. J. Bard and M. A. Fox., Acc. Chem. Rev. 28 (1995), 141.

[4] A. Hagfeld and M. Graetzel, Chem. Rev. 95 (1995), 49.

[5] O. Yakimova, A. Eremenko, and A. Chuiko, J. Mol. Str. 218 (1990), 447.

[6] A. Eremenko and A. Chuiko, Res. Chem. Intermed. 19 (1993), 375.

[7] D. R. Worrall, S. L. Williams, and F. Wilkinson, J. Phys. Chem., 99 (1995), 6689.

[8] G. Zhang, J. K. Thomas, A. Eremenko, T. Kikteva, and F. Wilkinson, J. Phys. Chem., 101 (1997), pp. 8569-8577;

a) M. A. T. Marro and J. K. Thomas, J. Photochem. Photobiol. A: Chem. 72 (1993), 251;

b) A. Eremenko, N. Smirnova, and V. Zabuga, unpublished results;

c) I. Tarasov, V. Kondilenko, and A. Eremenko, Theoret. Experim. Chem. 34 (1998), 23 (Russian, Transl. in English).

[9] D. R. Worrall, S. L. Williams, and F. Wilkinson, J. Phys. Chem. B 101 (1997), 4709.

[10] D. R. Worrall, S. L. Williams, and F. Wilkinson, J. Phys. Chem. A 102 (1998), 5484.

[11] D. R. Worrall, S. L. Williams, A. Eremenko, N. Smirnova, O. Yakimenko, and G. Starukh, Coll. Surf., in press.

[12] O. Yakimenko, N. Smirnova, A. Eremenko, V. Ogenko, A. Abdel-Shafi, D. Worrall, and F. Wilkinson, Theoret. Experim. Chem. 37 (2001), 176 (Russian, Transl. in English).

[13] C. J. Brinker and G. W. Scherer, Sol-Gel Science, Academic Press, New York, 1990.

[14] H. Sol-Gel Technology for Thin Films, Fibers, Performs, Electronics and Specialty Shapes; (L. C. Klein, ed.); Noyes Publication, Park Ridge, NJ, 1988.

[15] J. X. Gao, S. Bare, J. L. Fierro, M. Banares, and I. Wachs, JPC, B 102 (1998), 5653.

[16] C. Anderson and A. J. Bard, J. Phys. Chem. 99 (1995), 9882.

[17] C. Anderson and A. J. Bard, J. Phys. Chem. B 101 (1997), 2611.

[18] Z. Liu, J. Tabora, and R. G. Davis, J. Catal. 149 (1994), 117. 
[19] K. Kosuge and P. S. Singh, J. Phys. Chem. B. 103 (1999), 3563.

[20] A. Fernandez, A. Caballero, and A. R. GonzalesElipe, Surf. Interface Anal. 18 (1992), 392; Langmuir 9 (1993), 121.

[21] H. Weiss, A. Fernandez, and H. Kisch, Angewandte Chemie 40/20 (2001), 3825.
[22] O. Yakimova, A. Eremenko, and A. Chuiko, J. Mol. Str. 218 (1990), 447.

[23] S. A. Campbell, The Science and Engineering of Microelectronic Fabrication, Oxford Univ. Press, NY, 1996.

[24] S. L. Williams, Ph.D. Thesis, Loughborough University, 1996. 


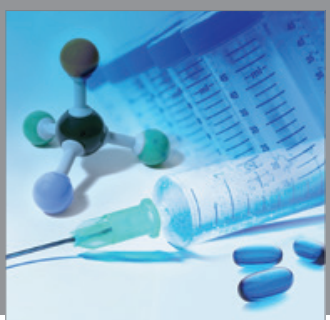

International Journal of

Medicinal Chemistry

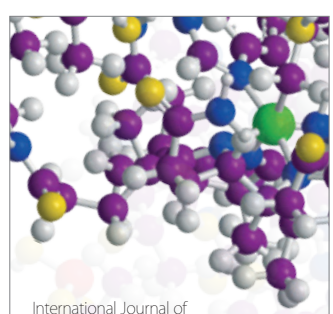

Carbohydrate Chemistry

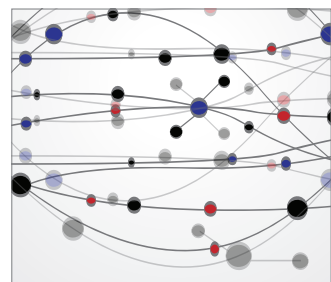

The Scientific World Journal
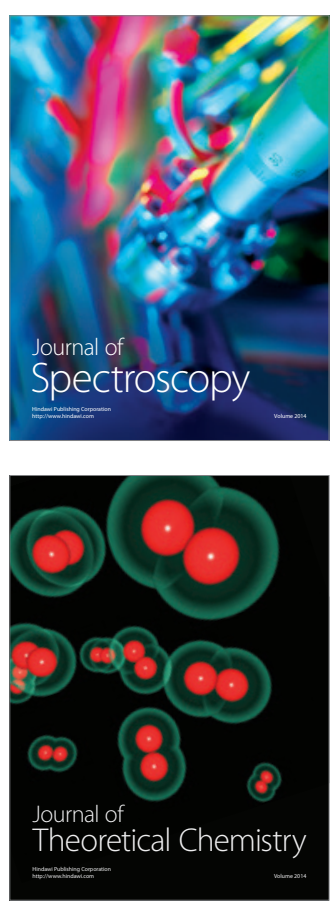
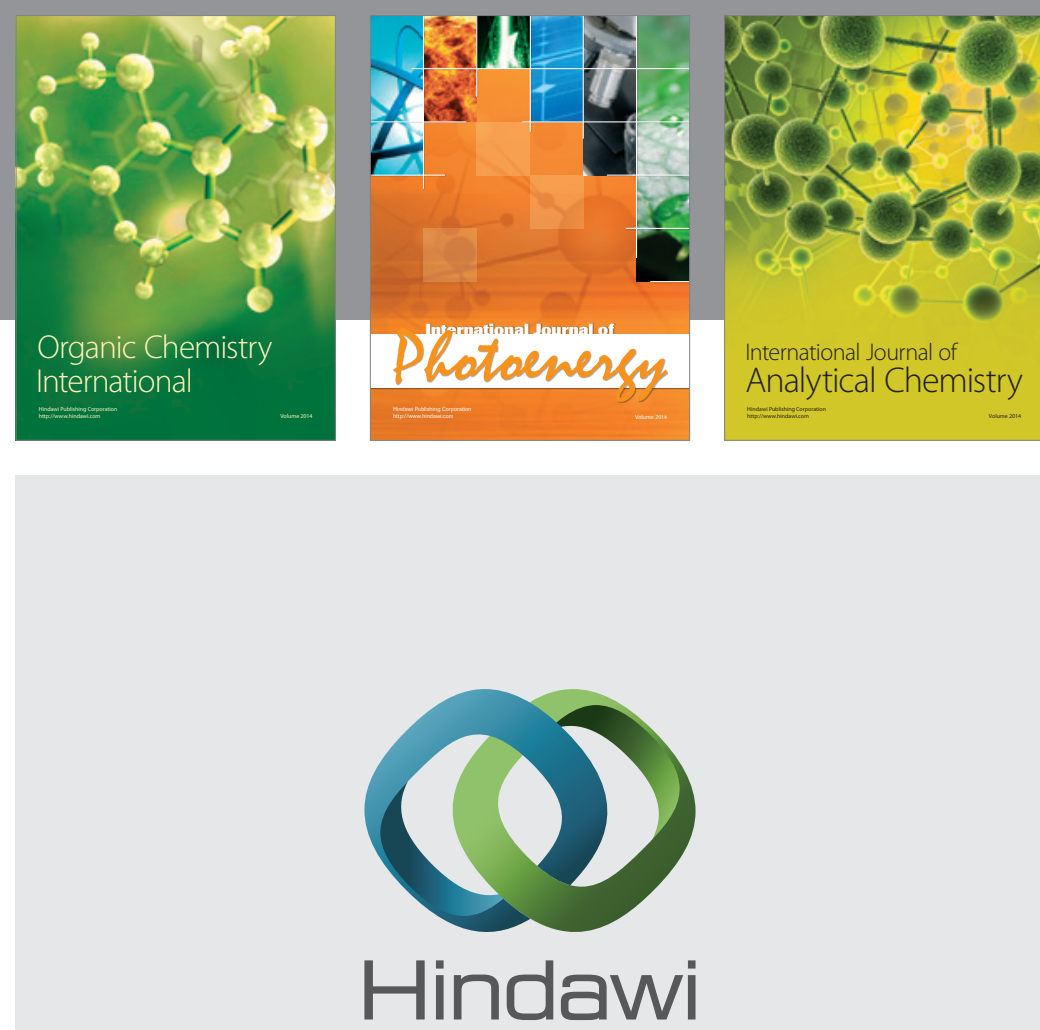

Submit your manuscripts at

http://www.hindawi.com
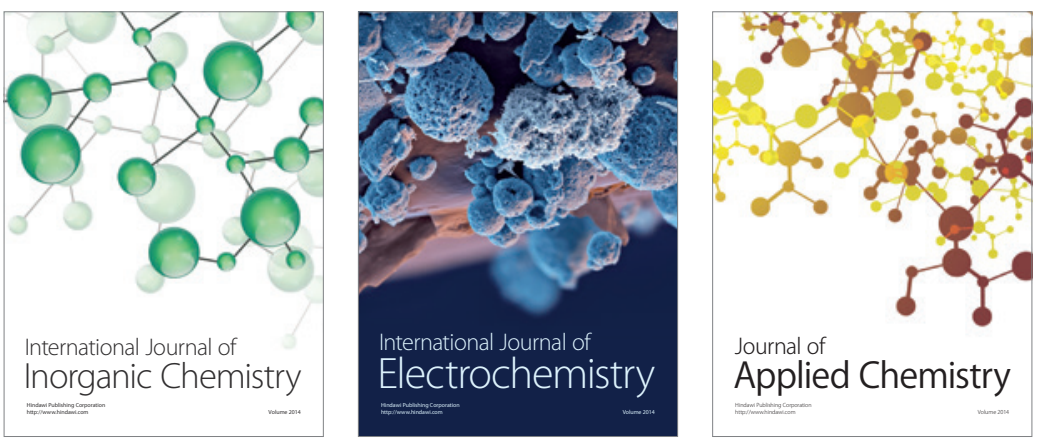

Journal of

Applied Chemistry
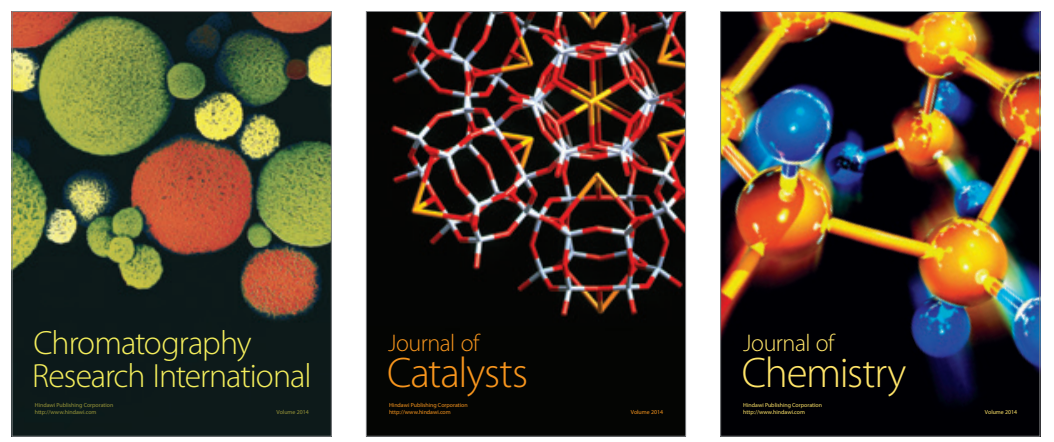
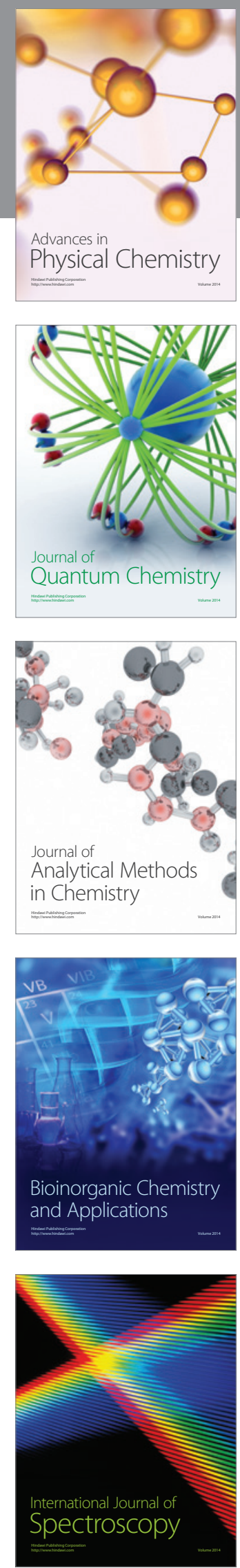